\title{
Effectiveness of Aroma Therapy on Depression among Old Age in Selected Old Age Home at Chennai
}

\author{
V. Hemavathy ${ }^{1}$, Lincy .S ${ }^{2}$ \\ ${ }^{1}$ Principal, Sree Balaji College of Nursing, Bharat University, Chennai, India \\ ${ }^{2}$ II nd Year M. Sc Nursing ,Sree Balaji College of Nursing, Bharat University, Chennai , India
}

\begin{abstract}
Background of the Study: Old age is not so full of energy, but things are settling and depth is arising. If you miss your youth, you will miss your old age. Home is the first school. Parents and grandparents are the first teachers. Grandparents are the one who teaches customs, culture, norms. New generation have less attachment with their elderly people as modern families are disintegrating into nuclear family. Objectives: To determine the pre test and post test level of depression among old age in the experimental and control group. To determine the effectiveness of aroma therapy on depression among old age in experimental and control group..To associate the post level of depression with the selected demographic variables of old age in the experimental group. Hypothesis $\mathrm{H}_{1}$ : The mean post test depression score of the old age will be significantly lesser than the mean pre test depression score of the old age who will have aroma. $\mathrm{H}_{2:}$ There will be a significant association between the post test depression level of the old age and their selected demographic variables. Methodology: Quasi experimental design was selected for this study. Purposive sampling technique was used for the study. Final Result And Conclusion: Depicts the pre test \& post test scores of both experimental \& control group. Among the experimental group majority of the samples (60\%) experienced mild level of depression and 12 out of $30(40 \%)$. But in the post test majority of the samples experienced mild level of depression (63\%), 11 out of 30 (37\%) experienced moderate level of depression. In control group in the pre test , majority of the samples experienced moderate level of depression (53\%) 14 out of $30(47 \%)$ in the post test, majority of the samples experienced moderate level of depression (57\%) experienced mild level of depression and 13 out of 30 (43\%). The effectiveness of aroma therapy on depression among 0ld age using paired " $t$ " test shows 10.5 significant at the level of $P<0.05$ Which implying that there was significant decrease in the level of depression in the post test.
\end{abstract}

Keywords: depression, effectiveness, aroma therapy, old age, old age home

\section{Introduction}

Aromatherapy is a form of alternative medicine that uses plant materials and aromatic plant oils, including essential oils, and other aromatic compounds for the purpose of altering one's mood, cognitive, psychological or physical wellbeing. Old age is not so full of energy, but things are settling and depth is arising. If you miss your youth, you will miss your old age..

\section{Objectives}

- To determine the pre test and post test level of depression among old age in the experimental and control group.

- To determine the effectiveness of aroma therapy on depression among old age in experimental and control group.

- To associate the post level of depression with the selected demographic variables of old age in the experimental group.

\section{Hypothesis}

$\mathrm{H}_{1}$ : The mean post test depression score of the old age will be significantly lesser than the mean pre test depression score of the old age who will have aroma.
$\mathrm{H}_{2}$ : There will be a significant association between the post test depression level of the old age and their selected demographic variables. (Age, sex, Marital status, Religion, Domicile, support system, Duration of stay in old age home, Performance of activities in daily living, Nature of admission, Education.)

\section{Methodology}

Quasi experimental design was selected for this study in Marias old age home, Chennai. The study population will comprise of old age in the age group of (50-70) years. Total sample size 30 both male and female old age are selected for the study by Purposive sampling technique. The questionnaire has 2 parts consisting of Demographic variables these are age ,sex, marital status, religion, domicile, support system, duration of stay in old age home, performance of activities ,nature of admission, education, in the second part of questionnaire geriatric depression scale was used .Interpretation of score was done as follow

\begin{tabular}{|c|c|}
\hline Category & Score \\
\hline Mild & $0-9$ \\
\hline Moderate & $10-19$ \\
\hline Severe & $20-30$ \\
\hline
\end{tabular}




\section{International Journal of Science and Research (IJSR) \\ ISSN (Online): 2319-7064 \\ Index Copernicus Value (2013): 6.14 | Impact Factor (2014): 5.611}

Table 3: Comparison of Pre test and post test level of depression in experimental and control group among old age

\begin{tabular}{|l|c|c|c|c|c|c|c|c|}
\hline \multirow{2}{*}{ Depression level } & \multicolumn{3}{|c|}{ Experimental group n=30 } & \multicolumn{5}{c|}{ Control group $\mathrm{n}=30$} \\
\cline { 2 - 10 } & \multicolumn{2}{|c|}{ Pre test } & \multicolumn{2}{c|}{ Post test } & \multicolumn{2}{c|}{ Pre test } & \multicolumn{2}{c|}{ Post test } \\
\hline & f & $\%$ & F & $\%$ & f & $\%$ & F & $\%$ \\
\hline mild 0-9 & 12 & 40 & 19 & 63 & 14 & 47 & 13 & 43 \\
\hline Moderate (10-19) & 18 & 60 & 11 & 37 & 16 & 53 & 17 & 57 \\
\hline Severe 20-30 & - & - & - & - & - & - & - & - \\
\hline
\end{tabular}

Depicts the pre test \& post test scores of both experimental \& control group. Among the experimental group majority of the samples (60\%) experienced mild level of depression and 12 out of $30(40 \%)$. But in the post test majority of the samples experienced mild level of depression (63\%), 11 out of 30 (37\%) experienced moderate level of depression. In control group in the pre test, majority of the samples experienced moderate level of depression (53\%) 14 out of $30(47 \%)$ in the post test, majority of the samples experienced moderate level of depression (57\%) experienced mild level of depression and 13 out of 30 ( 43\%) . Chi square $t$ value-10. 5 in experimental group,10.1 in control group.

\section{Major findings of the study}

Reveals that in experimental group majority ( $40 \%$ ) of the samples were in the age group of 50-55 years in experimental group and control group (50\%), (26.7\%) of samples belonged to the age group of 56-60 years in experimental group and control group (23.3\%), (23.3\%) of samples belong to age group of 61-65years in experimental group and control group (10\%), and (10\%) of samples belong to age group of 66-70 years in experimental group and control group (16.7\%). Regarding the sex status (73.3\%) of males in experimental and(40\%) in control group, and (26.7\%) of females belong to experimental group (60\%) in control group.. Regarding marital status about (43.3\%) were in the married in experimental group and control group (40\%).(13.3\%) were in the unmarried in experimental group and control group (10\%), (6.7\%) were in the divorced in experimental group and control group (10\%), (20\%) were in the separated in experimental group and control group (23.3\%), widow/widower criteria in experimental group (16.7)and (16.7\%) were in the widow criteria in control group. In the experimental groups the patients was Hindu by religion (73.3\%) in experimental group and control group( 63.3\%). Muslim by religion (6.7\%) in control group. Christian by religion (26.7\%) in experimental group and control group (30\%). In the groups most of the patients were hailing from urban (56.7\%) in experimental group and(66.7\%) in control group. Rural (43.3\%) in experimental group and (33.3\%) in control group. Regarding support system about (53.3\%) were in family support in experimental group and control group (43.3\%),(26.7\%) were in relatives support in experimental group and control group (26.7\%)\%),(10\%) were in friends support in experimental group and control group (20\%),(10\%) were in others support in experimental group and control group (10\%), Regarding the duration of stay in the old age home below 1 years (16.7\%) experimental group and control group(23.3\%) , 1-2 years (10\%) experimental group and control group(26.7\%), 2-3 years (6.7\%) experimental group and control group(10\%),3-4 years (20\%) experimental group and control group(10\%) (46.7\%)above 4years experimental group and control group(30\%) . Regarding performance of activities of daily living (86.7\%) independent experimental and control group (73.3\%), (13.3\%)partially independent in experimental and control group(26.7\%). Recording the nature of admission to the old age home (66.7\%) was in voluntary admission in experimental group(50\%)in control group, (33.3\%) forced by children's in experimental group (50\%) in control group. Regarding educational status were illiterate(30\%) experimental and control group (20\%), primary(10\%) experimental and control group (16.7\%), secondary(16.7\%) experimental and control group (20\%). Higher secondary(20\%) experimental and control group (30\%). graduate(23.3\%) experimental and control group (13.3\%).

\section{Conclusion}

Summarizes that the mean post test depression score 8.7 of the experimental group was lesser than mean post test depression score 10.7 of the control group. The obtained ' $t$ 'value 10.1 was statistically significant at 0.001 level. This indicates the mean difference of 0.4 is a true difference and has not occurred by chance.

\section{References}

[1] Albano A. M., et al. Old Age Depression Disorders. $5^{\text {th }}$ ed. New York: Guilford Press; 2003.

[2] Basavanthappa BJ. Nursing Research. $2^{\text {nd }}$ ed. New Delhi: Jaypee brothers publishers; 2009.

[3] Blazer D. Textbook of Clinical Psychology. $4^{\text {th }}$ ed. New York: American psychiatry publisher; 2003.

[4] Christensen Barbara \& Kockhow Elaine. Foundation of Nursing. $2^{\text {nd }}$ ed. Philadeiphia: Lippincott Company publisher; 1995.

[5] Clifford T.Morgan. Introduction to Psychology. $4^{\text {th }}$ ed. New York: Tata McGraw-Hill Publishing Company Ltd; 1993.

\section{Net References}

[6] http/www.pubmed.com

[7] http/www.google.com

[8] http/www.intelihealth.com 